\title{
The Impact of Circulating Tumor Cells on Venous Thromboembolism and Cardiovascular Events in Bladder Cancer Patients Treated with Radical Cystectomy
}

\author{
Michael Rink ${ }^{1, *}{ }^{1}$, Sabine Riethdorf ${ }^{2}$, Hang Yu ${ }^{1}$, Mara Kölker ${ }^{1}$, Malte W. Vetterlein ${ }^{1}{ }^{1}$, \\ Roland Dahlem ${ }^{1}$, Margit Fisch ${ }^{1}$, Klaus Pantel ${ }^{2}{ }^{10}$ and Armin Soave ${ }^{1}$ \\ 1 Department of Urology, University Medical Center Hamburg-Eppendorf, D-20246 Hamburg, Germany; \\ yuhang.seu@outlook.com (H.Y.); m.koelker@uke.de (M.K.); m.vetterlein@uke.de (M.W.V.); \\ r.dahlem@uke.de (R.D.); m.fisch@uke.de (M.F.); a.soave@uke.de (A.S.) \\ 2 Institute of Tumor Biology, University Medical Center Hamburg-Eppendorf, D-20246 Hamburg, Germany; \\ s.riethdorf@uke.de (S.R.); pantel@uke.de (K.P.) \\ * Correspondence: m.rink@uke.de; Tel.: +49-40-7410-53442; Fax: +49-40-7410-42444
}

Received: 7 October 2020; Accepted: 26 October 2020; Published: 28 October 2020

\begin{abstract}
Background: Cancer is a relevant risk factor for venous thromboembolism (VTE). Circulating tumor cells (CTC) are associated with an increased risk of VTE in breast cancer. In addition, circulating cell-free nucleic acids have been associated with cardiovascular events (CVE). Objective: To investigate the association of CTC status and the risk of VTE as well as CVE in urothelial carcinoma of the bladder (UCB) patients treated with radical cystectomy (RC). Methods: We collected data of $189 \mathrm{UCB}$ patients treated with RC at our institution. Blood samples were acquired preoperatively and analyzed for CTC using the CellSearch ${ }^{\circledR}$ system. Thirty-day postoperative complications were extracted from digital charts and graded according to the Clavien-Dindo classification (CDC). Moreover, each patient's individual Comprehensive Complication Index ${ }^{\circledR}\left(\mathrm{CCI}^{\circledR}\right)$ was calculated. Results: CTC were present in 43 patients $(22.8 \%)$. Overall, six patients experienced VTE (3.2\%) and eight patients (4.2\%) experienced CVE. There was no association of VTE or CVE according to CTC status. In total, 168 patients (89\%) experienced a total of 801 complications, of which the majority was classified as "minor" (CDC grade $\leq$ IIIa; 79\%). There was no association between CTC status and any grade of a complication or CCI ${ }^{\circledR}$. Presence of CTC was associated with more aggressive clinicopathological UCB features. Conclusions: The overall rate of VTE and CVE was low in our study. Presence of CTC was neither associated with an increased risk of VTE nor CVE in UCB patients treated with RC. According to this study, CTC are not a qualified biomarker for individualized thromboprophylaxis management in these patients.
\end{abstract}

Keywords: bladder cancer; urothelial carcinoma; circulating tumor cell; venous thromboembolism; cardiovascular event; radical cystectomy

\section{Introduction}

Radical cystectomy (RC) with or without perioperative chemotherapy is the gold standard treatment for muscle-invasive and recurrent refractory non-muscle invasive urothelial carcinoma of the bladder (UCB) [1]. Despite significant improvements in operative and perioperative management, RC denotes major pelvic surgery associated with high rates of intra- and postoperative complications [2]. Venous thromboembolism (VTE) and cardiovascular events (CVE) are relevant, potentially fatal complications frequently following major pelvic surgeries, including RC [3]. Indeed, apart from the surgical procedure, several cancers have been identified as an independent risk 
factor for thromboembolic events [4]. Tumor cells can activate hemostasis or fibrinolytic systems by variable mechanisms, including the production of procoagulant or pro-aggregating factors such as tissue factor cancer procoagulant and/or plasminogen activator inhibitors as well as the release of pro-inflammatory and proangiogenic cytokines $[5,6]$. Hence, peri- and postoperative pharmacological thromboprophylaxis is strongly recommended by international guidelines after RC [7].

Circulating tumor cells (CTC) are malignant epithelial cells, which represent an occult cancer burden in the peripheral blood stream. The presence of CTC is associated with unfavorable clinical outcomes in UCB patients treated with RC [8,9]. In metastatic breast cancer patients, the presence of CTC was found to be associated with an increased risk of VTE [10]. In addition, circulating cell-free nucleic acids (cf-NAs) in human plasma have been associated with cardiovascular disease [11]. Indeed, the introduction of a biomarker that identifies surgically treated patients with an additional cancer-related increased VTE or CVE risk would be of great clinical interest, as the clinical management and duration of perioperative thromboprophylaxis could be individually tailored. At present, the association of CTC and VTE or CVE has not been investigated in UCB. We hypothesized that UCB patients treated with RC and the presence of CTC harbor an increased risk for both endpoints.

\section{Materials and Methods}

\subsection{Study Population}

We prospectively collected the data of 219 UCB patients treated with RC and bilateral pelvic lymph node dissection at our institution between January 2007 and April 2014 and some other data were published before $[8,12,13]$. We previously described indication for $\mathrm{RC}$, preoperative patient workup, surgical intervention, and pathological workup [13]. A detailed description is provided as Supplementary Material. To investigate the unbiased morbidity outcomes from purely surgically treated patients, patients undergoing neoadjuvant chemotherapy were not eligible. The study was approved by the local ethics committee (Nb. PV3779).

\subsection{Blood Sample Analyses and CTC Investigations}

In general, one to seven days prior to $\mathrm{RC}$, all the patients received blood tests of various laboratory parameters. Blood coagulation tests included thrombocyte count (Mrd/L), INR (Quick), activated partial thromboplastin time (aPTT; seconds), thrombin time (TT; seconds), and fibrinogen measurement $(\mathrm{g} / \mathrm{L})$. The C-reactive protein $(\mathrm{CRP})$ is a systemic inflammatory response marker that is linked to tumorbiological features and outcome in UCB [14] and is associated with an increased risk of cancer-associated VTE [4]. The CRP assay was not standardized over time, but when available, high-sensitivity CRP was measured according to a method previously described [15]. CTC were detected using the CellSearch ${ }^{\circledR}$ system as previously described [8] (see also: Supplemental Material).

\subsection{Extraction and Grading of Complications}

Postoperative complications of 189 patients were extracted from digital charts. Any complication within the first 30 days after $\mathrm{RC}$ was recorded for each patient according to the predefined complication catalogue described by Vetterlein et al. [2]. Each complication was graded according to the validated and adapted Clavien-Dindo classification (CDC) [16,17]. In addition, we calculated the 30-day Comprehensive Complication Index ${ }^{\circledR}\left(\mathrm{CCI}^{\circledR}\right)[18]$ for each patient using the online calculator provided on http://cci.assessurgery.com. Based on the $\mathrm{CDC}$, the $\mathrm{CCI}^{\circledR}$ represents the perioperative course in a scale ranging from 0 (uneventful course) to 100 (death). Cause of death was determined by the treating physician, by chart review corroborated by death certificates, or by death certificates alone [19]. 


\subsection{Statistical Analysis}

The primary study endpoint was VTE defined as clinically apparent or diagnostic-confirmed deep venous thrombosis and/or pulmonary embolism. The coprimary endpoint was CVE defined as any myocardial infarction, new onset angina pectoris, cerebrovascular events, transient ischemic attack, or peripheral arterial ischemia.

The patient cohort was stratified according to CTC status (CTC presence vs. no presence). Clinical, pathological, and laboratory parameters were compared according to the CTC status as well as the coprimary endpoints. Due to the limited number of overall events, no further analyses according to the CTC number were employed. The clinical and laboratory parameters were also compared between patients experiencing one of the primary endpoints and those who did not. In addition, the overall preoperative morbidity burden as reflected by the $\mathrm{CDC}$ and $\mathrm{CCI}{ }^{\circledR}$ was analyzed and compared between both CTC groups.

All blood coagulation laboratory values were analyzed as continuous variables. CRP was analyzed as a continuous variable and dichotomized in low or high CRP-values. The cut-off for high CRP was $5 \mathrm{mg} / \mathrm{L}[15]$.

Continuous variables were reported as means and standard deviations or medians and interquartile ranges (IQRs). The Kolmogorov-Smirnov test was used to assess the normal distribution of variables. Categorical variables were presented as frequencies and proportions. For comparisons between the groups, a Chi-square test, Fisher's exact test, Student's t-test, and Mann-Whitney U test were used as appropriate. All reported $p$-values are two-sided, and statistical significance was set at $p<0.05$. All statistical tests were performed with IBM SPSS Statistics 25 (IBM Corp., Armonk, NY, USA).

\section{Results}

\subsection{Descriptive Characteristics of the Study Cohort}

Clinicopathologic characteristics of the entire study cohort and stratified according to CTC status are presented in Table 1 . The median age was 68 years and $137(73 \%)$ patients were male. Overall, $43(23 \%)$ patients had the presence of CTC with an average of $10 \pm 33$ cells/7.5 mL blood (median: 1 ; range: 1-163). Presence of CTC was associated with a higher rate of positive soft tissue surgical margin (STSM), presence of lymphovascular and microvascular invasion, and administration of adjuvant chemotherapy (all $p$-values $\leq 0.047$ ).

Table 1. Descriptive clinicopathological characteristics of 189 UCB patients who underwent radical cystectomy and bilateral lymphadenectomy.

\begin{tabular}{ccccc}
\hline & All & CTC Negative & CTC Positive & p-Value \\
& $N=\mathbf{1 8 9}$ & $\boldsymbol{N}=\mathbf{1 4 6}$ & $\mathbf{N 3}$ & \\
\hline Age (years; median (IQR)) & $68(58 ; 75)$ & $68(59 ; 75)$ & $70(57 ; 75)$ & 0.810 \\
\hline Gender $(n ; \%)$ & & & 0.333 \\
male & $137(72.5)$ & $103(70.5)$ & $34(79.1)$ & \\
female & $52(27.5)$ & $43(29.5)$ & $9(20.9)$ & \\
\hline ASA $(n ; \%)$ & $2(1.0)$ & $2(1.4)$ & 0.613 \\
1 & $95(50.3)$ & $76(52.1)$ & $19(44.2)$ & \\
2 & $89(47.1)$ & $66(45.2)$ & $23(53.5)$ & \\
3 & $3(1.6)$ & $2(1.4)$ & $1(2.3)$ & \\
4 & & & \\
\hline ECOG-PS $(n ; \%)$ & $169(89.4)$ & $133(91.1)$ & $36(83.7)$ & \\
0 & $20(10.6)$ & $13(8.9)$ & $7(16.3)$ & \\
\hline 1 & & &
\end{tabular}


Table 1. Cont.

\begin{tabular}{|c|c|c|c|c|}
\hline & $\begin{array}{c}\text { All } \\
N=189\end{array}$ & $\begin{array}{l}\text { CTC Negative } \\
\qquad N=146\end{array}$ & $\begin{array}{l}\text { CTC Positive } \\
\qquad N=43\end{array}$ & $p$-Value \\
\hline $\mathrm{ACCI}^{*}(n ; \%)$ & & & & 0.904 \\
\hline 0 & $5(2.6)$ & $4(2.7)$ & $1(2.3)$ & \\
\hline 1 & $18(9.5)$ & $13(8.9)$ & $5(11.6)$ & \\
\hline 2 & $25(13.2)$ & $20(13.7)$ & $5(11.6)$ & \\
\hline$\geq 3$ & $85(45.0)$ & $68(46.6)$ & $17(39.5)$ & \\
\hline $\begin{array}{l}\text { Intraoperative blood loss } \\
\quad(\mathrm{mL} ; \text { median }(\mathrm{IQR}))\end{array}$ & $500(200 ; 800)$ & $500(200 ; 800)$ & $550(300 ; 750)$ & 0.865 \\
\hline $\begin{array}{l}\text { Pathological Tumor Stage } \\
\qquad(n ; \%)\end{array}$ & & & & 0.090 \\
\hline pT0 & $19(10.1)$ & $18(12.3)$ & $1(2.3)$ & \\
\hline pTa & $11(5.8)$ & $8(5.5)$ & $3(7.0)$ & \\
\hline pTis & $10(5.3)$ & $9(6.2)$ & $1(2.3)$ & \\
\hline pT1 & $18(9.5)$ & $16(11.0)$ & $2(4.7)$ & \\
\hline pT2 & $45(23.8)$ & $32(21.9)$ & $13(30.2)$ & \\
\hline pT3 & $61(32.3)$ & $48(32.9)$ & $13(30.2)$ & \\
\hline pT4 & $25(13.2)$ & $15(10.3)$ & $10(23.3)$ & \\
\hline $\begin{array}{l}\text { Combined disease stage } \\
(n ; \%)\end{array}$ & & & & 0.296 \\
\hline Localized $(\leq \mathrm{pT} 2)$ & $103(54.5)$ & $83(56.8)$ & $20(46.5)$ & \\
\hline Advanced ( $\geq \mathrm{pT} 3)$ & $86(45.5)$ & $63(43.2)$ & $23(53.5)$ & \\
\hline $\begin{array}{l}\text { Pathological Tumor } \\
\text { Grade }(n ; \%)\end{array}$ & & & & 0.283 \\
\hline No grading (pT0) & $16(8.5)$ & $15(10.3)$ & $1(2.3)$ & \\
\hline $\mathrm{G} 2$ & $17(9.0)$ & $13(8.9)$ & $4(9.3)$ & \\
\hline G3 & $156(82.5)$ & $118(80.8)$ & $38(88.4)$ & \\
\hline $\begin{array}{c}\text { Concomitant carcinoma } \\
\text { in situ }(n)\end{array}$ & & & & 0.585 \\
\hline Absent & $123(65.1)$ & $97(66.4)$ & $26(60.5)$ & \\
\hline Present & $66(34.9)$ & $49(33.6)$ & $17(39.5)$ & \\
\hline Lymph node status $(n ; \%)$ & & & & 0.135 \\
\hline $\mathrm{pN} 0$ & $132(69.8)$ & $106(72.6)$ & $26(60.5)$ & \\
\hline $\mathrm{pN}+$ & $57(30.2)$ & $40(27.4)$ & $17(39.5)$ & \\
\hline $\begin{array}{l}\text { Number of lymph nodes } \\
\text { removed (median (IQR)) }\end{array}$ & $15(10 ; 22)$ & $15(10 ; 22)$ & $14(10 ; 22)$ & 0.427 \\
\hline Margin status $(n ; \%)$ & & & & 0.014 \\
\hline R0 & $163(86.2)$ & $131(89.7)$ & $32(74.4)$ & \\
\hline $\mathrm{R}+$ & $26(13.8)$ & $15(10.3)$ & $11(25.6)$ & \\
\hline $\begin{array}{l}\text { Lymphovascular invasion } \\
\qquad(n ; \%)\end{array}$ & & & & 0.041 \\
\hline Absent & $130(68.8)$ & $106(72.6)$ & $24(55.8)$ & \\
\hline Present & $59(31.2)$ & $40(27.4)$ & $19(44.2)$ & \\
\hline $\begin{array}{c}\text { Microvascular invasion } \\
(n ; \%)\end{array}$ & & & & 0.047 \\
\hline Absent & $163(86.2)$ & $130(89.0)$ & $33(76.7)$ & \\
\hline Present & $26(13.8)$ & $16(11.0)$ & $10(23.3)$ & \\
\hline $\begin{array}{c}\text { Adjuvant Chemotherapy } \\
(n ; \%)\end{array}$ & & & & 0.007 \\
\hline No & $137(72.5)$ & $113(77.4)$ & $24(55.8)$ & \\
\hline Yes & $52(27.5)$ & $33(22.6)$ & $19(44.2)$ & \\
\hline
\end{tabular}

Abbreviations: UCB — urothelial carcinoma of the bladder; CTC—circulating tumor cells; IQR—interquartile range; ASA-American Society of Anesthesiologists; ECOG-PS-Eastern Cooperative Oncology Group Performance Status; ACCI—Age-adjusted Charlson comorbidity index. * ACCI was not available for $56(29.6 \%)$ patients. Bold characters indicate statistical significance. 


\subsection{Primary Endpoint Analyses}

In total, six (3.2\%) VTE occurred in all patients, among which four patients $(2.1 \%)$ had deep venous thrombosis, one patient $(0.5 \%)$ had pulmonary embolism, and one patient $(0.5 \%)$ had both deep venous thrombosis and pulmonary embolism, respectively. In total, eight patients (4.2\%) experienced CVE (Table 2).

Table 2. Comparative analysis of venous thromboembolism, cardiovascular events, and laboratory index parameters of 189 UCB patients treated with radical cystectomy and bilateral lymphadenectomy stratified by CTC status.

\begin{tabular}{|c|c|c|c|c|}
\hline & $\begin{array}{c}\text { All } \\
N=189\end{array}$ & $\begin{array}{c}\text { CTC Negative } \\
\qquad N=146\end{array}$ & $\begin{array}{l}\text { CTC Positive } \\
\qquad N=43\end{array}$ & $p$-Value \\
\hline $\begin{array}{l}\text { Venous Thromboembolism } \\
\qquad(n ; \%)\end{array}$ & & & & 0.132 \\
\hline No & $183(96.8)$ & 143 (97.9) & $40(93.0)$ & \\
\hline Yes & $6(3.2)$ & $3(2.1)$ & $3(7.0)$ & \\
\hline Deep vein thrombosis & $4(2.1)$ & $2(1.4)$ & $2(4.7)$ & \\
\hline Pulmonary embolism & $1(0.5)$ & $1(0.7)$ & $0(0)$ & \\
\hline Both & $1(0.5)$ & $0(0)$ & $1(2.3)$ & \\
\hline Cardiovascular Events $(n ; \%)$ & & & & 0.685 \\
\hline No & $181(95.8)$ & 139 (95.2) & 42 (97.7) & \\
\hline Yes & $8(4.2)$ & $7(4.8)$ & $1(2.3)$ & \\
\hline Myocardial Infarction & $1(0.5)$ & $1(0.7)$ & $0(0)$ & \\
\hline Angina pectoris & $2(1.1)$ & $2(1.4)$ & $0(0)$ & \\
\hline CVA/TIA & $3(1.6)$ & $2(1.4)$ & $1(2.3)$ & \\
\hline $\begin{array}{l}\text { Angina pectoris and } \\
\text { Myocardial Infarction }\end{array}$ & $1(0.5)$ & $1(0.7)$ & $0(0)$ & \\
\hline $\begin{array}{c}\text { Angina pectoris and } \\
\text { CVA/TIA }\end{array}$ & $1(0.5)$ & $1(0.7)$ & $0(0)$ & \\
\hline $\begin{array}{l}\text { C-reactive protein } \\
(\mathrm{mg} / \mathrm{L} ; \text { median }(\mathrm{IQR}))\end{array}$ & $1(1 ; 11.5)$ & $1(1 ; 11)$ & $7(1 ; 14)$ & 0.137 \\
\hline Low $(n ; \%)$ & $114(60.3)$ & $93(63.7)$ & $21(48.8)$ & 0.08 \\
\hline $\operatorname{High}(n ; \%)$ & $75(39.7)$ & $53(36.3)$ & $22(51.2)$ & \\
\hline $\begin{array}{l}\text { Thrombocyte } \\
\text { (Mrd/L; median) }\end{array}$ & 282 & 277 & 298 & 0.213 \\
\hline Quick (INR; median) & 0.97 & 0.97 & 0.98 & 0.442 \\
\hline APTT (s; median) & 29.13 & 28.86 & 30.07 & 0.016 \\
\hline TT (s; median) & 17.60 & 17.68 & 17.31 & 0.145 \\
\hline Fibrinogen (g/L; median) & 4.25 & 4.12 & 4.72 & 0.007 \\
\hline
\end{tabular}

Abbreviations: UCB-urothelial carcinoma of the bladder; CTC—circulating tumor cells; CVA—cerebrovascular accident; TIA—transient ischemic attack; IQR—interquartile range; INR-international normalized ratio; APTT—activated partial thromboplastin time; TT—-thrombin time. Bold characters indicate statistical significance.

Three of $43(7.0 \%)$ patients with presence of CTC experienced a VTE and 1/43 (2.3\%) patients experienced a CVE, respectively; both were not significantly different from patients without CTC presence (Table 2). In patients with CTC presence, the aPTT was longer (30.1 vs. $28.9 \mathrm{~s}, p=0.016$ ) and the fibrinogen level was higher ( 4.72 vs. $4.12 \mathrm{~g} / \mathrm{L}, p=0.007)$ compared to patients without CTC presence. Table 3 summarizes the results of clinical and laboratory index parameters for the subgroups of patients with VTE and CVE, compared to patients without any of these events. The patient cohort was homogenously distributed without statistically significant differences in age, gender, duration of RC (OR-time), American Society of Anesthesiologists (ASA), Eastern Cooperative Oncology Group (ECOG), or Age-adjusted Charlson comorbidity index (ACCI) scores between patients with or without any VTE or CVE, respectively. There was no statistically significant difference in any laboratory value for all analyzed comparisons. 
Table 3. Analyses of clinical and laboratory index parameter in patients with venous thromboembolic or cardiovascular events after radical cystectomy for UCB treatment.

\begin{tabular}{|c|c|c|c|c|}
\hline Parameter & $\begin{array}{c}\text { All } \\
N=189\end{array}$ & Subgroup & All Others & $p$ \\
\hline & & VTE (6 pts) & No VTE (183 pts) & \\
\hline Age (year; median (IQR)) & $68(58 ; 75)$ & $73(53 ; 76)$ & $68(60 ; 75)$ & 0.796 \\
\hline Male gender $(n ; \%)$ & $137(72.5)$ & $5(3.6)$ & $132(96.4)$ & 0.889 \\
\hline $\operatorname{ASA}(n ; \%)$ & & & & 0.981 \\
\hline 1 & $2(1.0)$ & $0(0)$ & $2(1.1)$ & \\
\hline 2 & $95(50.3)$ & $3(50.0)$ & $92(50.3)$ & \\
\hline 3 & $89(47.1)$ & $3(50.0)$ & $86(47.0)$ & \\
\hline 4 & $3(1.6)$ & $0(0)$ & $3(1.6)$ & \\
\hline $\mathrm{ECOG} \geq 1(n ; \%)$ & $20(10.6)$ & $0(0)$ & $20(100)$ & 0.506 \\
\hline $\mathrm{ACCI}^{*}(n ; \%)$ & & & & 0.355 \\
\hline 0 & $5(2.6)$ & $0(0)$ & $5(2.7)$ & \\
\hline 1 & $18(9.5)$ & $2(33.3)$ & $16(8.7)$ & \\
\hline 2 & $25(13.2)$ & $0(0)$ & $25(13.7)$ & \\
\hline$\geq 3$ & $85(45)$ & $4(66.7)$ & $81(44.3)$ & \\
\hline OR-Time (median; IQR) & $273(225 ; 335)$ & $244(189 ; 316)$ & $275(225 ; 335)$ & 0.292 \\
\hline $\begin{array}{l}\text { C-reactive protein } \\
(\mathrm{mg} / \mathrm{L} ; \text { median }(\mathrm{IQR}))\end{array}$ & $1(1 ; 12)$ & $6(1 ; 35)$ & $1(1 ; 11)$ & 0.518 \\
\hline Low $(n ; \%)$ & $114(60.3)$ & $3(50.0)$ & $111(60.7)$ & 0.920 \\
\hline $\operatorname{High}(n ; \%)$ & $75(39.7)$ & $3(50.0)$ & $72(39.3)$ & \\
\hline $\begin{array}{l}\text { Thrombocyte } \\
\text { (Mrd/L; median) }\end{array}$ & 282 & 323 & 281 & 0.295 \\
\hline Quick (INR; median) & 0.97 & 1.07 & 0.97 & 0.344 \\
\hline APTT (s; median) & 29.10 & 29.70 & 29.10 & 0.654 \\
\hline TT (s; median) & 17.60 & 17.60 & 17.60 & 0.996 \\
\hline \multirow[t]{2}{*}{ Fibrinogen (g/L; median) } & 4.25 & 4.47 & 4.25 & 0.665 \\
\hline & & CVE (8 pts) & No CVE (181 pts) & \\
\hline Age (year; median (IQR)) & $68(58 ; 75)$ & $75(55 ; 82)$ & $68(60 ; 75)$ & 0.333 \\
\hline Male gender $(n ; \%)$ & $137(72.5)$ & $5(62.5)$ & 132(72.9) & 0.809 \\
\hline $\operatorname{ASA}(n ; \%)$ & & & & 0.889 \\
\hline 1 & $2(1.0)$ & $0(0)$ & $2(1.1)$ & \\
\hline 2 & $95(50.3)$ & $5(62.5)$ & $90(49.7)$ & \\
\hline 3 & $89(47.1)$ & $3(37.5)$ & $86(47.5)$ & \\
\hline 4 & $3(1.6)$ & $0(0)$ & $3(1.7)$ & \\
\hline $\mathrm{ECOG} \geq 1(n ; \%)$ & $20(10.6)$ & $2(10)$ & $18(90)$ & 0.443 \\
\hline $\mathrm{ACCI}^{*}(n ; \%)$ & & & & 0.397 \\
\hline 0 & $5(2.6)$ & $0(0)$ & $5(2.8)$ & \\
\hline 1 & $18(9.5)$ & $2(25)$ & $16(8.8)$ & \\
\hline 2 & $25(13.2)$ & $0(0)$ & $25(13.8)$ & \\
\hline$\geq 3$ & $85(45)$ & $5(62.5)$ & $80(44.2)$ & \\
\hline OR-Time (median; IQR) & $273(225 ; 335)$ & $283(259 ; 354)$ & $275(225 ; 335)$ & 0.592 \\
\hline $\begin{array}{c}\text { C-reactive protein } \\
(\mathrm{mg} / \mathrm{L} ; \text { median }(\mathrm{IQR}))\end{array}$ & $1(1 ; 12)$ & $12(3 ; 20)$ & $1(1 ; 11)$ & 0.068 \\
\hline Low $(n ; \%)$ & $114(60.3)$ & $2(25)$ & $112(61.9)$ & 0.086 \\
\hline $\operatorname{High}(n ; \%)$ & $75(39.7)$ & $6(75)$ & $69(38.1)$ & \\
\hline
\end{tabular}


Table 3. Cont.

\begin{tabular}{ccccc}
\hline Parameter & $\begin{array}{c}\text { All } \\
\mathbf{N = 1 8 9}\end{array}$ & Subgroup & All Others & $p$ \\
\hline $\begin{array}{c}\text { Thrombocyte } \\
\text { (Mrd/L; median) }\end{array}$ & 282 & 299 & 281 & 0.606 \\
\hline Quick (INR; median) & 0.97 & 0.97 & 0.97 & 0.991 \\
\hline APTT (s; median) & 29.10 & 28.70 & 29.10 & 0.668 \\
\hline TT (s; median) & 17.60 & 17.40 & 17.60 & 0.654 \\
\hline Fibrinogen (g/L; median) & 4.25 & 4.95 & 4.22 & 0.106 \\
\hline
\end{tabular}

Abbreviations: UCB—urothelial carcinoma of the bladder; VTE—venous thromboembolism; IQR-interquartile range; ASA-American Society of Anesthesiologists; ECOG-PS-Eastern Cooperative Oncology Group Performance Status; ACCI—Age-adjusted Charlson comorbidity index; INR—international normalized ratio; APTT—activated partial thromboplastin time; TT—-thrombin time; CVE—cardiovascular Events. * ACCI was not available for 56 $(29.6 \%)$ patients.

\subsection{Evaluation of All 30-Day Postoperative Complications}

In total, 801 complications were captured in 168 patients $(89 \%)$, which translated into a median of 4 (IQR 2-6) complications per patient. The most common complications types were infectious (18.9\%), gastrointestinal (18.6\%), and genitourinary (18.1\%) complications, respectively (Supplementary Table S1). Table 4 presents a summary of the 30-day postoperative complications graded by CDC for the entire study cohort and stratified by CTC status. In total, seventeen patients (8.9\%) experienced the most severe complications (CDC grade $\geq \mathrm{IIIb}$ ) requiring another intervention under general anesthesia and an additional two patients (1.1\%) had fatal complications and died during the early postoperative course (CDC grade V). The majority of complications, however, were graded "minor" (CDC grade I: $14.8 \%$; CDC grade II: $60.8 \%$; CDC grade IIIa: $3.2 \%$ ). There was no difference among any grade of complications between CTC positive and negative patients.

Table 4. CDC grading and $\mathrm{CCI}^{\circledR}$ score of 30-day postoperative complications in 189 UCB patients who underwent radical cystectomy between 2007 and 2013.

\begin{tabular}{ccccc}
\hline & All & CTC Negative & CTC Positive & \multirow{2}{*}{-Value } \\
& $\boldsymbol{N}=\mathbf{1 8 9}$ & $\boldsymbol{N}=\mathbf{1 4 6}$ & $\mathbf{N = 4 3}$ & \\
\hline CDC grading & & & & 0.996 \\
0 & $21(11.1)$ & $17(11.6)$ & $4(9.3)$ & \\
Grade I & $28(14.8)$ & $22(15.1)$ & $6(14.0)$ & \\
Grade II & $115(60.8)$ & $87(59.6)$ & $28(65.1)$ & \\
Grade IIIa & $6(3.2)$ & $5(3.4)$ & $1(2.3)$ & \\
Grade IIIb & $12(6.3)$ & $9(6.2)$ & $3(7.0)$ & \\
Grade IVa & $5(2.6)$ & $4(2.7)$ & $1(2.3)$ & \\
Grade IVb & $0(0)$ & $0(0)$ & $0(0)$ & \\
Grade V & $2(1.1)$ & $2(1.4)$ & $0(0)$ & \\
\hline CCI (median & 27.2 & 27.2 & 25.7 & \multirow{2}{*}{0.537} \\
(IQR)) & $(18.4 ; 34.3)$ & $(17.3 ; 34.3)$ & $(20.9 ; 30.8)$ &
\end{tabular}

Abbreviations: CDC-Clavien-Dindo classification; CCI-Comprehensive Complication Index; UCB —urothelial carcinoma of the bladder; CTC—-irculating tumor cells.

The median $\mathrm{CCI}^{\circledR}$ considering all complications for the entire cohort was 27.2 (IQR: 18.4;34.3). The median $\mathrm{CCI}^{\circledR}$ for patients with presence of CTC was lower compared to patients without CTC presence, which did not reach statistical significance ( $25.7 \mathrm{vs.} 27.2 ; p=0.54)$. In the subgroup of patients experiencing a VTE, the median $\mathrm{CCI}^{\circledR}$ was higher compared to patients without a VTE (35.6 (IQR: $32.2 ; 60.2)$ vs. $25.7(17.3 ; 33.2) ; p=0.002)$. In the subgroup of patients experiencing a CVE, the median $\mathrm{CCI}^{\circledR}$ also exceeded the $\mathrm{CCI}^{\circledR}$ for patients without a CVE (44.6 (IQR: 34.0;70.8) vs. 25.7 (17.3;33.2); $p=0.03)$. 


\section{Discussion}

We found that presence of CTC was not associated with an increased risk of VTE in our cohort. Thus, we have to reject our null hypothesis. In general, several malignancies including UCB are highly associated with a tumor-induced increased risk for VTE [4]. The pathogenesis of cancer-associated VTE is multifactorial and likely involves multiple overlapping pathways including Virchow's triad, surgery- or chemotherapy-induced endothelial damage, cancer-related immobility, and cancer-induced hypercoagulability [4]. Malignant tumor cells can activate a direct coagulation pathway, inhibit fibrinolytic activity, and induce inflammatory responses in various complex ways, respectively, of which each single or a combination may trigger VTE. Thus, it intuitively seemed reasonable to investigate the association between CTC and VTE, as today, in the absence of reliable evidence, all UCB patients receive the same recommendation regarding medical antithrombotic prophylaxis [7]. A biomarker, therefore, would be helpful for a personalized risk assessment and individually tailored decision-making regarding risk of VTE and duration of prophylaxis. The VTE rate in our cohort $(3.2 \%)$ is in congruence with the incidence after RC depending on preexisting risk factors in the literature (2.6-11.6\%) [20]. Our findings are in contrast to a study in metastatic breast cancer patients, in which CTC detected by the CellSearch ${ }^{\circledR}$ system were significantly associated with an increased risk of VTE [10]. Differences between the study by Mego et al. and ours include the underlying tumor entity, status of disease, and type of treatment among others, which may explain differential findings. Especially in early UCB stages, CTC occur in very low concentrations in the peripheral blood [21]. Next to the cancer itself, in UCB, the highest risk of VTE is reported in patients undergoing RC, due to numerous surgical factors. We, therefore, investigated potential confounding clinical and surgical factors including age, preexisting morbidity, and operation time and found no difference between patients experiencing a VTE and those who did not in all parameters. Indeed, the limited numbers of patients with CTC presence and primary endpoint events may have masked significant associations in our study.

Despite cancer-induced VTE being substantially more pervasive, cardiovascular disease due to the presence of malignancy, chemotherapeutic drugs, and cancer-related comorbidities represents a relevant clinical issue. In fact, according to a recent population-based study among various cancer entities, UCB patients have the highest risk of dying from a cardiovascular disease [22]. Circulating cf-NAs have been reported to offer promising new insights in the regulation of normal physiological functions and in the development of pathological alterations. Thus, they may allow diagnosis and monitoring for various cardiovascular diseases [11]. In UCB, next to cell-free tumor DNA and RNA, CTC are another encouraging real-time blood-based biomarker that reflects potentially occult metastatic disease [9] and better predicted overall survival compared to other circulating biomarkers including cf-DNA [23]. We, therefore, investigated the associations of CTC and CVE in our study. We found that CTC presence was not associated with CVE in our cohort. Although the CVE rate in our study is in line with previous reports $[2,24]$, the absolute event rate is limited, which may have concealed significant associations and also interfered further detailed analyses for this heterogeneous group of events. In fact, CTC and cf-NAs do not indiscriminately reflect the same source of origin and therefore, may predict variable endpoints. CTC usually represent epithelial cells that can be distinguished from other blood cells by various technical mechanisms and therefore, identify malignant tumor burden originating from the primary tumor or its metastasis. In contrast, cf-NAs in cancer patients do not only originate only from tumor cells, but also from cells of the tumor microenvironment and non-cancer cells from various parts of the body [25]. In patients with cardiovascular disease, an increased rate of cf-NAs may be released into circulation from dying cells during normal cellular turnover or active cell death, especially in the case of acute ischemic vascular events. In addition, the surgical procedure itself also may increase the cf-NA rate after RC. A detailed analysis of the origin of cf-NA would be warranted in UCB patients to discriminate between cancer-derived cf-NAs and other origins. Unfortunately, we were unable to include cf-NA analyses in this study to investigate differential findings compared to CTC. 
We analyzed various laboratory parameters that are commonly used in clinical routine to investigate their association with CTC status and both study endpoints, respectively. We found a higher median fibrinogen level in patients with presence of CTC, without any association to VTE or CVE. Various cancers including UCB may activate the coagulation/fibrinolysis system, with fibrinogen being an acute phase protein performing a relevant step in the coagulation process. It has been reported that increased preoperative plasma fibrinogen levels are associated with adverse tumorbiological features [26] and a risk factor for 1-year mortality after RC in UCB patients [27]. In congruence, the increased fibrinogen level in our study may reflect the more aggressive tumorbiological features in CTC-positive patients, including higher rates of $\mathrm{pT} 4$ and $\mathrm{pN}+$ disease, positive surgical margins as well as the presence of LVI and microvessel invasion, although not all of these parameters were statistically significantly different from CTC-negative patients. Moreover, we found an elevated median of aPTT in patients with CTC presence. The aPTT is a coagulation test measuring the general speed at which blood clots, by means of the intrinsic and common pathways of coagulation, among others, monitor the treatment effects of heparin. Shortened aPTT times may indicate consumption and have been reported to be associated with an increased risk of thrombosis [28]. The oncological meaning of aPTT remains ambiguous, especially in urological malignancies [29]. Since aPTT was not associated with VTE, CVE, or any other clinicopathologic variable, we rate our finding as rather unspecific to avoid overestimation. The independent oncological prognostic relevance of both laboratory parameters in UCB patients treated with RC might be interesting and therefore, the object of future studies in larger cohorts, but this was not the subject of this study. Unfortunately, we were unable to include other popular biomarkers in our study such as D-Dimer, a potentially predictive marker for VTE risk [4].

Our data confirm the overall tremendous risk of morbidity after RC. Almost $90 \%$ of patients had a median of four complications within 30-days after surgery. This rate is substantially higher compared to previous reports [24], which may be due to our meticulous assessment of 30-day complications after RC according to the revised Martin criteria of the updated European Association of Urology (EAU) guidelines using a digital patient chart. We used a refined analysis of complications compared to previous studies, as we analyzed complications using the $\mathrm{CDC}$ and $\mathrm{CCI}^{\circledR}$ score, respectively. Next to the CDC grading of only the highest complication during a specified time frame, we also mirrored a patient's cumulative morbidity burden using the $\mathrm{CCI}^{\circledR}$ to reduce underreporting [2]. In congruence with the existing literature, the broad majority of complications were classified as "minor" according to CDC and only $9 \%$ had a complication CDC grade $\geq \mathrm{IIIl}$. As the quality and quantity of a complication are paramount, the $\mathrm{CCI}^{\circledR}$ provides a more intuitive reflection of the perceived overall morbidity. Indeed, it is debatable whether every single undesirable event should be considered a complication. Still, we found that with patients experiencing a VTE or CVE, both had significantly higher $\mathrm{CCI}^{\circledR}$ scores compared to patients without these complications. While this primarily indicates a larger amount and/or more severe complications in these patients, it also underscores the utmost importance of preoperative screening for cardiovascular diseases in UCB patients [22] as well as various perioperative approaches to minimizing the VTE risk [3]. In contrast, we found no difference in $\mathrm{CDC}_{\text {or }} \mathrm{CCI}^{\circledR}$ between patients with or without CTC presence. Although this intuitively is not surprising, it is an important piece of information considering the fact that the presence of CTC is a powerful predictor for inferior outcomes [8] and thus, CTC-positive patients may be candidates for adjuvant chemotherapy [13].

Although to our knowledge, this is the first study investigating the association of CTC with VTE and CVE in UCB patients treated with RC, this study is not devoid of limitations. First and foremost are limitations inherent to the overall sample size and event rates. Some clinical and laboratory factors (e.g., family history of thrombosis or lupus anticoagulant) were not routinely assessed in all patients, which may have influenced study endpoints. Obviously, complications do also occur $>30$ days after RC. We chose 30 days to be able to extract the most possible granular data from our digitalized charts and to mitigate information loss during retrospective data extraction due to recall bias and documentation quality [2]. In addition, VTE and CVE usually occur early during the postoperative course and the majority of these events are captured in the first 3 weeks post-surgery [30,31]. Nevertheless, 
a reevaluation of the association of CTC with both endpoints in the intermediate- and long-term post-RC interval may be of great interest. In addition, perioperative administration of low-weight molecular heparin on a regular basis may have masked significant associations between CTC and outcomes. All patients in our study were treated by open RC, which may have influenced results, as differences in the risk of VTE and CVE between open and laparoscopic or robotic-assisted RC have been reported [7]. If CTC dissemination is also influenced by the type of RC currently remains unclear. In addition, our study did not include patients treated with neoadjuvant chemotherapy. Indeed, complication rates as well as CTC measures may vary in patients undergoing neoadjuvant chemotherapy. To improve the generalizability of our findings, larger studies including patients with neoadjuvant chemotherapy and different types of surgery are desirable. Finally, our results rely on investigations using the CellSearch ${ }^{\circledR}$ system, which still remains the only validated, FDA-approved technology for the detection of CTC. Nevertheless, there are different commercially available platforms with variable CTC detection rates [9]. While malignant CTC in the peripheral blood stream may be missed by the CellSearch ${ }^{\circledR}$ platform, it also still needs to be proven that every epithelial cell detected with this system truly is a malignant CTC.

\section{Conclusions}

According to our study, CTC are not associated with an increased risk of VTE or CVE in UCB patients treated with RC. As a consequence, CTC do not seem to represent a biomarker for individually tailored medical prophylaxis to minimize the risk of cancer-associated VTE or CVE in patients after RC. However, the limited number of patients with presence of CTC as well as VTE and CVE events in our study warrant reevaluation in a larger patient cohort.

Supplementary Materials: Supplementary Materials can be found at http://www.mdpi.com/2077-0383/9/11/ 3478/s1. Supplementary Material and Methods; Supplemental Table S1. Frequencies, proportions, therapeutic management, and grading of perioperative 30-day complications in 189 patients who underwent radical cystectomy between January 2007 and December 2013.

Author Contributions: Conceptualization, M.R. and A.S.; data curation, M.R., S.R. and A.S.; formal analysis, M.R., H.Y. and M.W.V.; investigation, M.R., S.R. and A.S.; methodology, M.R.; project administration, M.R. and A.S.; supervision, M.R. and S.R.; validation, M.R., H.Y. and M.W.V.; writing-original draft, M.R., H.Y. and A.S.; writing-review and editing, M.R., S.R., H.Y., M.K., M.W.V., R.D., M.F., K.P. and A.S. All authors have read and agreed to the published version of the manuscript.

Funding: This research received no external funding.

Conflicts of Interest: The authors declare no conflict of interest.

\section{References}

1. Witjes, J.A.; Bruins, H.M.; Cathomas, R.; Comperat, E.M.; Cowan, N.C.; Gakis, G.; Hernandez, V.; Espinos, E.L.; Lorch, A.; Neuzillet, Y.; et al. European Association of Urology Guidelines on Muscle-invasive and Metastatic Bladder Cancer: Summary of the 2020 Guidelines. Eur. Urol. 2020. [CrossRef] [PubMed]

2. Vetterlein, M.W.; Klemm, J.; Gild, P.; Bradtke, M.; Soave, A.; Dahlem, R.; Fisch, M.; Rink, M. Improving Estimates of Perioperative Morbidity After Radical Cystectomy Using the European Association of Urology Quality Criteria for Standardized Reporting and Introducing the Comprehensive Complication Index. Eur. Urol. 2020, 77, 55-65. [CrossRef] [PubMed]

3. Tikkinen, K.A.O.; Craigie, S.; Agarwal, A.; Violette, P.D.; Novara, G.; Cartwright, R.; Naspro, R.; Siemieniuk, R.A.C.; Ali, B.; Eryuzlu, L.; et al. Procedure-specific Risks of Thrombosis and Bleeding in Urological Cancer Surgery: Systematic Review and Meta-analysis. Eur. Urol. 2018, 73, 242-251. [CrossRef] [PubMed]

4. Ay, C.; Pabinger, I.; Cohen, A.T. Cancer-associated venous thromboembolism: Burden, mechanisms, and management. Thromb. Haemost. 2017, 117, 219-230. [CrossRef]

5. Bystricky, B.; Reuben, J.M.; Mego, M. Circulating tumor cells and coagulation-Minireview. Crit. Rev. Oncol./ Hematol. 2017, 114, 33-42. [CrossRef] 
6. Haubold, K.; Rink, M.; Spath, B.; Friedrich, M.; Chun, F.K.; Marx, G.; Amirkhosravi, A.; Francis, J.L.; Bokemeyer, C.; Eifrig, B.; et al. Tissue factor procoagulant activity of plasma microparticles is increased in patients with early-stage prostate cancer. Thromb. Haemost. 2009, 101, 1147-1155. [PubMed]

7. Tikkinen, K.A.O.; Cartwright, R.; Gould, M.K.; Naspro, R.; Novara, G.; Sandset, P.M.; Violette, P.D.; Guyatt, G.H. EAU Guidelines on Thromboprophylaxis in Urological Surgery, Proceedings of the 32nd EAU Annual Meeting, London, UK, 2017; EAU Guidelines Office: Arnhem, The Netherlands, 2017.

8. Rink, M.; Chun, F.K.; Dahlem, R.; Soave, A.; Minner, S.; Hansen, J.; Stoupiec, M.; Coith, C.; Kluth, L.A.; Ahyai, S.A.; et al. Prognostic Role and HER2 Expression of Circulating Tumor Cells in Peripheral Blood of Patients Prior to Radical Cystectomy: A Prospective Study. Eur. Urol. 2012, 61, 810-817. [CrossRef]

9. Rink, M.; Schwarzenbach, H.; Riethdorf, S.; Soave, A. The current role and future directions of circulating tumor cells and circulating tumor DNA in urothelial carcinoma of the bladder. World J. Urol. 2019, 37, 1785-1799. [CrossRef]

10. Mego, M.; De Giorgi, U.; Broglio, K.; Dawood, S.; Valero, V.; Andreopoulou, E.; Handy, B.; Reuben, J.M.; Cristofanilli, M. Circulating tumour cells are associated with increased risk of venous thromboembolism in metastatic breast cancer patients. Br. J. Cancer 2009, 101, 1813-1816. [CrossRef]

11. Biro, O.; Hajas, O.; Nagy-Balo, E.; Soltesz, B.; Csanadi, Z.; Nagy, B. Relationship between cardiovascular diseases and circulating cell-free nucleic acids in human plasma. Biomark. Med. 2018, 12, 891-905. [CrossRef]

12. Soave, A.; Riethdorf, S.; Dahlem, R.; Minner, S.; Weisbach, L.; Engel, O.; Fisch, M.; Pantel, K.; Rink, M. Detection and oncological effect of circulating tumour cells in patients with variant urothelial carcinoma histology treated with radical cystectomy. BJU Int. 2017, 119, 854-861. [CrossRef] [PubMed]

13. Soave, A.; Riethdorf, S.; Dahlem, R.; von Amsberg, G.; Minner, S.; Weisbach, L.; Engel, O.; Fisch, M.; Pantel, K.; Rink, M. A nonrandomized, prospective, clinical study on the impact of circulating tumor cells on outcomes of urothelial carcinoma of the bladder patients treated with radical cystectomy with or without adjuvant chemotherapy. Int. J. Cancer 2017, 140, 381-389. [CrossRef] [PubMed]

14. Saito, K.; Kihara, K. C-reactive protein as a biomarker for urological cancers. Nat. Rev. Urol. 2011, 8, 659-666. [CrossRef] [PubMed]

15. Mbeutcha, A.; Shariat, S.F.; Rieken, M.; Rink, M.; Xylinas, E.; Seitz, C.; Lucca, I.; Mathieu, R.; Roupret, M.; Briganti, A.; et al. Prognostic significance of markers of systemic inflammatory response in patients with non-muscle-invasive bladder cancer. Urol. Oncol. Semin. Orig. Investig. 2016, 34, 483.e17-483.e24. [CrossRef]

16. Dindo, D.; Demartines, N.; Clavien, P.A. Classification of surgical complications: A new proposal with evaluation in a cohort of 6336 patients and results of a survey. Ann. Surg. 2004, 240, 205-213. [CrossRef]

17. Clavien, P.A.; Barkun, J.; de Oliveira, M.L.; Vauthey, J.N.; Dindo, D.; Schulick, R.D.; de Santibanes, E.; Pekolj, J.; Slankamenac, K.; Bassi, C.; et al. The Clavien-Dindo classification of surgical complications: Five-year experience. Ann. Surg. 2009, 250, 187-196. [CrossRef]

18. Slankamenac, K.; Graf, R.; Barkun, J.; Puhan, M.A.; Clavien, P.A. The comprehensive complication index: A novel continuous scale to measure surgical morbidity. Ann. Surg. 2013, 258, 1-7. [CrossRef]

19. Rink, M.; Fajkovic, H.; Cha, E.K.; Gupta, A.; Karakiewicz, P.I.; Chun, F.K.; Lotan, Y.; Shariat, S.F. Death certificates are valid for the determination of cause of death in patients with upper and lower tract urothelial carcinoma. Eur. Urol. 2012, 61, 854-855. [CrossRef]

20. Zareba, P.; Duivenvoorden, W.C.M.; Pinthus, J.H. Thromboembolism in Patients with Bladder Cancer: Incidence, Risk Factors and Prevention. Bladder Cancer 2018, 4, 139-147. [CrossRef]

21. Riethdorf, S.; Soave, A.; Rink, M. The current status and clinical value of circulating tumor cells and circulating cell-free tumor DNA in bladder cancer. Transl. Androl. Urol. 2017, 6, 1090-1110. [CrossRef]

22. Sturgeon, K.M.; Deng, L.; Bluethmann, S.M.; Zhou, S.; Trifiletti, D.M.; Jiang, C.; Kelly, S.P.; Zaorsky, N.G. A population-based study of cardiovascular disease mortality risk in US cancer patients. Eur. Heart J. 2019, 40, 3889-3897. [CrossRef]

23. Azevedo, R.; Soares, J.; Peixoto, A.; Cotton, S.; Lima, L.; Santos, L.L.; Ferreira, J.A. Circulating tumor cells in bladder cancer: Emerging technologies and clinical implications foreseeing precision oncology. Urol. Oncol. Semin. Orig. Investig. 2018, 36, 221-236. [CrossRef] [PubMed]

24. Shabsigh, A.; Korets, R.; Vora, K.C.; Brooks, C.M.; Cronin, A.M.; Savage, C.; Raj, G.; Bochner, B.H.; Dalbagni, G.; Herr, H.W.; et al. Defining early morbidity of radical cystectomy for patients with bladder cancer using a standardized reporting methodology. Eur. Urol. 2009, 55, 164-174. [CrossRef] 
25. Bronkhorst, A.J.; Ungerer, V.; Holdenrieder, S. The emerging role of cell-free DNA as a molecular marker for cancer management. Biomol. Detect. Quantif. 2019, 17, 100087. [CrossRef] [PubMed]

26. Liu, J.; Li, D.; Cao, L.; Wang, Z.; Li, Y.; Liu, H.; Chen, G. Elevated preoperative plasma fibrinogen level is an independent predictor of malignancy and advanced stage disease in patients with bladder urothelial tumors. Int. J. Surg. 2016, 36, 249-254. [CrossRef]

27. Zhu, Z.; Wang, X.; Wang, J.; Wang, S.; Fan, Y.; Fu, T.; Cao, S.; Zhang, X. Preoperative predictors of early death risk in bladder cancer patients treated with robot-assisted radical cystectomy. Cancer Med. 2019, 8, 3447-3452. [CrossRef]

28. Campello, E.; Henderson, M.W.; Noubouossie, D.F.; Simioni, P.; Key, N.S. Contact System Activation and Cancer: New Insights in the Pathophysiology of Cancer-Associated Thrombosis. Thromb. Haemost. 2018, 118, 251-265. [CrossRef] [PubMed]

29. Alevizopoulos, A.; Tyritzis, S.; Leotsakos, I.; Anastasopoulou, I.; Pournaras, C.; Kotsis, P.; Katsarou, O.; Alamanis, C.; Stravodimos, K.; Constantinides, C. Role of coagulation factors in urological malignancy: A prospective, controlled study on prostate, renal and bladder cancer. Int. J. Urol. 2017, 24, 130-136. [CrossRef]

30. Amin, A.N.; Lenhart, G.; Princic, N.; Lin, J.; Thompson, S.; Johnston, S. Retrospective administrative database study of the time period of venous thromboembolism risk during and following hospitalization for major orthopedic or abdominal surgery in real-world US patients. Hosp. Pract. 2011, 39, 7-16. [CrossRef]

31. Devereaux, P.J.; Mrkobrada, M.; Sessler, D.I.; Leslie, K.; Alonso-Coello, P.; Kurz, A.; Villar, J.C.; Sigamani, A.; Biccard, B.M.; Meyhoff, C.S.; et al. Aspirin in patients undergoing noncardiac surgery. N. Engl. J. Med. 2014, 370, 1494-1503. [CrossRef]

Publisher's Note: MDPI stays neutral with regard to jurisdictional claims in published maps and institutional affiliations. 